La galaxie de rumeurs, d'Axel Grysperdt et Annabelle Klein. Éditions Vie Ouvrière, collection EVO Communication, Bruxelles, 1996, 176 pages,

\title{
124 Francs
}

Hugues Hotier

\section{OpenEdition}

\section{Journals}

Édition électronique

URL : http://journals.openedition.org/communicationorganisation/1860

DOI : 10.4000/communicationorganisation. 1860

ISSN : 1775-3546

Éditeur

Presses universitaires de Bordeaux

Édition imprimée

Date de publication : 1 mai 1996

ISSN : 1168-5549

Référence électronique

Hugues Hotier, «La galaxie de rumeurs, d'Axel Grysperdt et Annabelle Klein. Éditions Vie Ouvrière collection EVO Communication, Bruxelles, 1996, 176 pages, 124 Francs », Communication et organisation [En ligne], 9 | 1996, mis en ligne le 26 mars 2012, consulté le 19 avril 2019. URL : http:// journals.openedition.org/communicationorganisation/1860 ; DOI : 10.4000/ communicationorganisation. 1860

Ce document a été généré automatiquement le 19 avril 2019

(c) Presses universitaires de Bordeaux 


\title{
La galaxie de rumeurs, d'Axel Grysperdt et Annabelle Klein. Éditions Vie Ouvrière, collection EVO Communication, Bruxelles, 1996, 176 pages, 124 Francs
}

\author{
Hugues Hotier
}

1 «Susurrez le mot «rumeur», de nombreux commentaires fuseront. Tout le monde «sait» ou «sent» de quoi il s'agit, chacun peut en dire quelque chose. Tapotez ces six lettres sur un clavier en bibliothèque, l'écran déroulera une impressionnante bibliographies d'ouvrages repérés par ce terme. Au moins Annabelle klein sait que cet ouvrage, préfacé par Jules Gritti, ne traite pas d'un thème nouveau. Ce n'est pas une raison pour ne pas ajouter une pierre à l'édifice de la connaissance. Axel Grysperdt, qui dirigea la publication des actes du colloque « Fumées sans feu » et les publia sous le titre Rumeurs médiatisées (Editions Labor-Isis, Liège, 1994) pense lui aussi que tout n'a pas été dit et qu'il convient régulièrement de réexaminer les sujets que l'actualité nous impose.

2 L'ouvrage, auquel trois autres chercheurs de Comu, le département de communication de l'Université Catholique de Louvain, ont prêté leur concours, comporte à la fois des développements théoriques et des études de cas. Il s'articule autour des thèmes suivants : rumeur et mythe, rumleur et symbole, rumeur et presse écrite, rumeur et rite, rumeur et argumentation, rumeur et communication. Chacune de ces parties a un auteur identifié, Annabelle Klein étant la plus présente à la table des matières.

3 C'est un livre bien écrit, homogène malgré la multiplicité des auteurs et qui dose avec bonheur la distanciation de la conceptualisation et l'immédiateté de l'analyse de contenu.

L'adresse des Editions Vie Ouvrière est la suivante :

5 EVO Editions, 4, rue d'Anderlecht, 1000 Bruxelles (Belgique)

6 Tel : (32) 2. / 5125090 - Fax : 5145231 